\title{
RELATO DE EXPERIÊNCIA NO ESTÁGIO SUPERVISIONADO I NO ENSINO INFANTIL
}

\author{
RELATO DE EXPERIENCIA EN LA ETAPA SUPERVISADA I EN LA \\ ENSEÑANZA INFANTIL
}

\section{EXPERIENCE REPORT SUPERVISED STAGE ONE ON TEACHING FOR CHILDREN}

\author{
Francisco Claudeci Faustino TEIXEIRA ${ }^{1}$ \\ Ana Paula Mendes SANTIAGO ${ }^{2}$ \\ Jacqueline de Oliveira LIMA ${ }^{3}$ \\ Stela Lopes SOARES ${ }^{4}$ \\ Heraldo Simões FERREIRA ${ }^{5}$
}

RESUMO: Este trabalho científico priorizou descrever as práticas saudáveis dentro da disciplina de Estágio Supervisionado I, na Educação Infantil, que ocorreram no Centro Educacional Dolores Lustosa. Tendo estas vivências, no campo de atuação, pautado no interesse em conhecer a realidade de um determinado espaço que é contemplado ao profissional de Educação Física por lei. Este trabalho teve como objetivo proporcionar uma reflexão sobre o que rege as práticas saudáveis, dentro do Estágio Supervisionado I em Educação Física Licenciatura no ensino infantil e abrir discussões sobre os processos de observação, coparticipação e docência supervisionada, realizadas durante o Estágio Supervisionado I, visando o desenvolvimento integral da criança. A metodologia utilizada neste estudo foi à pesquisa-ação. Optou-se pelo o tratamento dos achados de forma qualitativa como meio de aproximação do objeto de estudo, através de observação participante de duas turmas do infantil IV, "B" e "D". Durante as aulas propostas foram utilizadas atividades lúdicas e recreativas, adequadas à faixa etária das crianças, selecionadas segundo uma proposta saudável de estímulos às habilidades motoras básicas, as necessidades de interação e participação dos alunos. Ao termino da pesquisa percebe-se nas crianças, uma evolução em tais aspectos como na participação, interação e uma contribuição significativa no processo de socialização.

PALAVRAS-CHAVE: Estágio supervisionado I. Educação física. Práticas saudáveis, Educação infantil.

\footnotetext{
${ }^{1}$ Universidade Estadual Vale Acaraú (UVA) - Sobral - CE - Brasil. Graduando em Educação Física. Email: claudecyr10@gmail.com.

${ }^{2}$ Universidade Estadual Vale Acaraú (UVA) - Sobral - CE - Brasil. Graduada em Educação Física. Email: paulacarpes2@gmail.com.

${ }^{3}$ Universidade Estadual Vale Acaraú (UVA) - Sobral - CE - Brasil. Graduanda em Educação Física. Email:Jacque@live.com.

${ }^{4}$ Universidade Estadual do Ceara (UECE) - CE - Brasil. Mestranda em Ensino na Saúde. E-mail: stelalopesoares@hotmail.com.

${ }^{5}$ Universidade Estadual do Ceara (UECE) - CE - Brasil. Professor Adjunto do Curso de Educação Física. Doutor em Saúde Coletiva pela Universidade Estadual do Ceará. E-mail: heraldo.simoes@uece.br.
} 
RESUMEN: Este trabajo científico priorizó describir las prácticas saludables dentro de la disciplina de Etapa Supervisionada I, en la Educación Infantil, que ocurrieron en el Centro Educativo Dolores Lustosa. Con estas vivencias en el campo de actuación pautado en el interés en conocer la realidad de un determinado espacio que contempla al profesional de Educación Física por ley. Este trabajo tuvo como objetivo proporcionar una reflexión sobre lo que rige las prácticas saludables dentro de la Etapa Supervisionado I en Educación Física Licenciatura en la enseñanza infantil y abrir discusiones sobre los procesos de observación, coparticipación y docencia supervisada, realizadas durante la Etapa Supervisada I, visando El desarrollo integral del niño. La metodología utilizada en este estudio fue la investigación-acción. Se optó por el tratamiento de los hallazgos de forma cualitativa como medio de aproximación del objeto de estudio, a través de observación participante de dos clases del infantil IV, "B" $y$ " $D$ ". Durante las clases propuestas se utilizaron actividades lúdicas y recreativas, adecuadas al grupo de edad de los niños, seleccionados según una propuesta sana de estímulos a las habilidades motoras básicas, las necesidades de interacción y participación de los alumnos. Al término de la investigación se percibe en los niños, una evolución en tales aspectos como en la participación, interacción y una contribución significativa en el proceso de socialización.

PALABRAS CLAVE: Etapa supervisión I. Educación física. Prácticas saludables. Educación infa

ABSTRACT: This scientific work prioritized to describe the healthy practices within the discipline of Supervised Internship One, in Early Childhood Education, that took place in the Dolores Lustosa Educational Center. Having these experiences in the field of action based on the interest in knowing the reality of a certain space that contemplates the professional of Physical Education by law. The objective of this study was to provide a reflection on healthy practices within the Supervised Internship One in Physical Education Degree in early childhood education and to open discussions on the observation, coparticipation and supervised teaching processes carried out during Supervised Internship One, aiming at the integral development of the child. The methodology used in this study was to action research. The qualitative treatment of the findings was chosen as a means of approaching the object of study, through participant observation of two classes of children IV, " $B$ " and " $D$ ". During the classes proposed were used recreational activities, appropriate to the age range of children, selected according to a healthy proposal of stimuli to basic motor skills, the interaction needs and participation of the students. At the end of the research it is noticed in the children, an evolution in such aspects as participation, interaction and a significant contribution in the socialization process.

KEYWORDS: Supervised internship one. Physical education. Healthy practices. Early childhood education.

\section{Introdução}

Este trabalho trata-se de um relato de experiência sobre a organização e desenvolvimento dentro das práticas saudáveis da disciplina do Estágio Supervisionado 
I do curso de Licenciatura em Educação Física na modalidade a presencial da Universidade Estadual Vale do Acaraú-UVA, Sobral-Ce.

O Estágio Supervisionado é o momento em que o acadêmico pratica todos os aprendizados assimilados durante a formação universitária, ou seja, nessa etapa ele se exercita e se aperfeiçoa os métodos, técnicas e estratégias para o seu progresso profissional (AZOLINI, 2012).

A aproximação entre a comunidade Acadêmica e o Centro de Educação Infantil Dolores Lustosa aconteceu primeiramente por meio de uma reunião com o responsável pelos os estágios da Instituição de Ensino Superior - IES e a diretora da Creche. Nesse princípio foi negociada a efetivação das atividades saudáveis do Estágio Supervisionado I no Ensino Infantil.

Em momento de acordos e comunicação entre os membros envolvidos, foi firmada a ida do Acadêmico-estagiário até o Centro de Educação Infantil Dolores Lustosa para conversar com a diretora e supervisora sobre quais os horários poderiam ser disponibilizados na concretização das ações saudáveis propostas.

Chegando à Creche me identifiquei como Acadêmico do Curso de Educação Física, os gestores já estavam me esperando devido às intermediações primárias mencionadas anteriormente, foram bem receptivos com a proposta de estágio da universidade. Deu-se pleiteado pelos os responsáveis da instituição os dias de segundafeira e quarta-feira pela manhã durante quinze dias para conclusão do Estágio.

O Centro de Educação Infantil oferta ensino regular para crianças nos turnos manhã e tarde, onde são dividas as turmas em faixas etárias no método de construção do conhecimento. Os profissionais facilitadores são pedagogos formados e acadêmicos estagiários das áreas envolvidas na constituição educadora. Em sala de aula tem um professor para turma e quando existe um aluno que demanda uma atenção individualizada, é disponibilizado mais um profissional exclusivamente para aquele discente.

As crianças têm aula das 7 horas às 11 horas da manhã, neste período, no âmbito escolar, são organizados momentos de recreação em um parquinho que fica localizado no pátio da instituição, antes das vivências tem também o lanche. A recreação é sistematizada com duas turmas ao mesmo tempo durando quinze minutos sequenciando as turmas até que o final da jornada escolar, até que todas as turmas tenham participado das recreações no parquinho.

$\mathrm{Na}$ atuação em campo, foram efetuadas observações nos períodos de aulas dos 
alunos em duas salas do Ensino Infantil IV. Durante esse contato direto com os discentes, utilizou-se uma caderneta de anotações, onde foram anotados todos os acontecimentos ocorridos no espaço na qual dentro destes fatos foi também anotado quais possíveis práticas saudáveis que pudessem contribuir com o desenvolvimento estudantil no processo de ensino aprendizagem, destas possíveis atividades foram selecionadas quatro atividades promotoras de saúde envolvendo jogos e brincadeiras lúdicas para a construção e aplicação do plano de aula com as duas turmas observadas.

Nas Diretrizes Curriculares Nacionais dos cursos de Licenciatura, o Estágio Supervisionado constitui o processo de transição profissional, que procura ligar duas lógicas (educação e trabalho) e que proporciona ao estudante a oportunidade de treinar as competências e habilidades que já detém sob supervisão de um profissional da área.

É importante desenvolver nos alunos, futuros professores, habilidades para o conhecimento e análise das escolas, espaço institucional, onde ocorre o ensino e a aprendizagem. Envolve, também, o conhecimento, a utilização e a avaliação de técnicas, métodos e estratégias de ensinar em situações diversas. Envolve habilidade de leitura e reconhecimento das teorias presentes nas práticas pedagógicas das instituições. $\mathrm{O}$ estágio, assim realizado, permite que se traga contribuição de pesquisas e o desenvolvimento das habilidades de pesquisar (PIMENTA; LIMA, 2005/2006, p. 20).

A disciplina de Estágio Supervisionado no Ensino Infantil é uma ferramenta de prática docente que busca contemplar os diversos aspectos envolvendo o possível trabalho que o professor de Educação Física pode desenvolver dentro de um Centro Educacional Infantil, já que a Educação Física Escolar tem esta disciplina na grade curricular, mas não é legitimado por políticas educativas a exercer este cargo essencial.

É o Estágio que proporciona ao acadêmico o momento de vivência de educador ativo no desenvolvimento de indivíduos criativos e capazes de atuar no meio em que habitam; não é só uma projeção de saberes. O Estágio no processo de formação inicial deve gerar o contato pratico com a realidade reflexiva sobre o porquê das suas atividades e respostas no cotidiano ao qual estão inseridos (ALVES, 2012).

Este artigo tem como objetivo proporcionar uma reflexão sobre o que rege as práticas saudáveis, dentro do Estágio Supervisionado I em Educação Física Licenciatura no ensino infantil e abrir discussões sobre os processos de observação, coparticipação e docência supervisionada, que atualmente são essenciais em todos os âmbitos do processo de formação dos futuros docentes. 


\section{Método}

Este estudo caracteriza-se como uma pesquisa-ação, que tem como propósito produzir informações e conhecimentos de uso mais efetivo, inclusive ao nível pedagógico e de promoção de saúde no âmbito Escolar, que promove condições para ações e transformações de situações dentro do próprio Centro Educacional. Baseada nas teorias de Piaget, Vygotsk e Henri Wallon, foram organizadas e realizadas atividades saudáveis voltadas para as necessidades das crianças, considerados os aspectos físicos, psicológicos, intelectuais e sociais. Para o planejamento das atividades ainda foram consideradas as observações das aulas convencionais, ministradas pelas educadoras (pedagogas), responsável pelas turmas do infantil IV "B" e “D” do Centro Educação Infantil Dolores Lustosa, em Sobral-Ce.

Tripp (2005) ressalta que, na pesquisa-ação, o pesquisador tende a se envolver na constituição dos achados, tendo esse a consciência que ao escolher e contextualizar os dados terá que aplicar de volta todos os novos conhecimentos adquiridos naquele determinado âmbito educacional.

\section{Amostra}

Este estudo foi realizado no Centro de Educação Infantil Dolores Lustosa dentro das propostas de práticas saúdaveis emetarias da disciplina: Estágio Supervionado I do Curso de Licenciatura em Educação Física da Universidade Estadual Vale da AcaraúUVA. O Centro de Educação Infantil Dolores Lustosa fica localizado na Rua Raimundo Nonato dos Santos, 70, Cidade Dr. Jose Euclides II, Sobral, Ceará. Esta Instituição atende criaças da creche e pré-escola, sendo de ambos os sexos. Durante a efetivação deste escopo foram garantidos todos os principios éticos e morais dos membros envolvidos no estudo.

O Conselho Nacional de Saúde (2012) afirma que em todo estudo cientifico, o pesquisador tem por maior das finalidades, respeitar os princípios éticos e morais dos seres humanos envolvidados na pesquisa cientifica para garantir fidegnidade dos dados coletados.

\section{Instrumentos}


Utilizou-se como procedimento estratégico a observação inicial diagnóstica, que ocorreu no período de 18 de fevereiro a 2 de março de 2016, com o objetivo de identificar as atividades e ações desenvolvidas pelas professoras do ensino infantil.

Analisados os dados registrados nas observações em duas turmas do Infantil IV "B" e "D", com duração de 4 horas em cada turma, prossegui com a elaboração dos planos de aulas definindo os jogos e brincadeiras lúdicas como patente das atividades planejadas. Também foram construídas estratégias para avaliar os resultados, o que se deu através da reflexão sobre cada um dos aspectos envolvidos. Isso contribui de forma significativa para o aperfeiçoamento da ação e auxilia na construção de projetos de aula que preenchessem lacunas observadas na abordagem tradicional feita no ensino infantil.

\section{Procedimentos}

A Ementa da disciplina de Estágio Supervisionado I contém como atividade sustentadora, a realização de Estagio pelos acadêmicos nos centros de ensino infantil, sejam eles públicos ou privados. Onde os acadêmicos autorizados por meio de um oficio, expedido pela Universidade e assinado por um responsável da instituição pretendida, são distribuídos por meio de um sorteio, para as instituições de ensino infantil para a realização das vivências no âmbito futuro da docência e, ao concluírem, esses acadêmicos tem que apresentarem na sala de aula a realidade defrontada no campo de atuação.

Foram analisados os dados registrados nas observações em duas turmas do Infantil IV "B" e "D”, com duração de 4 horas em cada turma, prossegui a elaboração dos planos de aulas definindo os jogos e brincadeiras lúdicas como patente, visando a pratica saudável em promoção de saúde no âmbito escolar. Também foram construídas estratégias para avaliar os resultados, o que se deu através da reflexão sobre cada um dos aspectos envolvidos. Isso contribui de forma significativa para o aperfeiçoamento da ação e auxiliar na construção de projetos de aula que preenchessem lacunas observadas na abordagem tradicional feita no ensino infantil.

Os jogos e as brincadeiras lúdicas têm um valor considerado para o ensino infantil, pois são ferramentas das quais podemos trabalhar por meio pedagógico o desenvolvimento, crescimento, aprendizagem e a conscientização para o bem-estar das crianças, isto porque estes fazem parte do mundo da criança, para elas a brincadeira não 
é diferente da realidade, pois elas não sabem distinguir, os jogos fazem parte de sua vida (ROCHA, 2010).

Com os planos de aulas prontos, foi negociado com os professores responsáveis por cada turma qual seria o melhor horário para a intervenção, após o diálogo, ficou fechado que as intervenções fossem efetuadas depois da primeira aula.

A primeira intervenção aconteceu com o Infantil IV “D” e segunda intervenção aconteceu com o Infantil IV "B" no dia 29 de fevereiro e 2 de março de 2016 respectivamente com duração de 30 minutos em cada intervenção e tendo 30 alunos participantes em cada turma.

A princípio as crianças ficaram bem tímidas, não compreendiam as atividades e os jogos saudáveis. Ao longo do processo, esta barreira inicial foi sendo transposta. As crianças passaram a demonstrar maior interesse durante as atividades planejadas e a se mostraram bem mais participativas. No que diz respeito à execução das atividades pelas crianças, algumas dificuldades foram diagnosticadas, problemas relacionados à movimentação, equilíbrio e socialização. Isso nos remeteu à uma reflexão sobre o fato da disciplina Educação Física não existir enquanto componente pedagógico e não estar inserida no cotidiano da escola. A experiência das crianças sobre os aspectos da cultura corporal e movimento ficam restritos a um único momento, a "hora do movimento", termo que designa o período de vinte minutos durante os quais se realizam atividades lúdicas.

\section{Análise estatística}

Os resultados foram registrados em forma de relatório onde se encontram descritos o processo de planejamento e intervenção, assim como uma descrição sucinta e contextualizada sobre a relevância da realização do estágio na educação infantil.

\section{Resultados}

Uma das coisas que mais me chamou atenção durante esse período de estágio foi quando cheguei à creche Dolores Lustosa e me dirigi a uma das salas, chegando naquele espaço me identifiquei como acadêmico do curso de Educação Física - Licenciatura da Universidade Estadual Vale do Acaraú - UVA. Diante disso, eu expliquei para a docente que a educação física na Educação Infantil é regida pela a Lei de Diretrizes e 
Bases da Educação (LDB) e não apenas porque existia na nossa grade curricular do curso. Percebe-se que a docente teve uma atitude de como se esteve sendo incomodada pela presença de um profissional de outra área.

Outro fato bastante marcante aconteceu no início das atividades saudáveis no pátio da instituição, as crianças interagiam durante a atividade planejada em plano de aula, a coordenadora começa a observar à participação dos alunos e solicitar para a mesma docente citada acima, por sua atitude irônica, para registrar através de fotos tudo o que acontece durante a concretização das ações pensadas pelo o estagiário.

A cada prática promotora de saúde aplicada com os alunos, Professores, Supervisores e Diretora da Creche explanava para a importância de se estar sendo introduzidos conteúdos novos no período de aula dos discentes, a ordem dada para o estagiário era "proporcione o máximo de conteúdos inovadores que você conseguir efetivar".

\section{Discussão}

\section{A educação física como instrumento saudável na educação infantil}

Na contemporaneidade, a Educação Infantil vem sendo foco de diversos estudos científicos. Toda essa atenção é devida por ser um dos estágios mais complexos do desenvolvimento humano; que requer um olhar pedagógico especializado nos aspectos físicos, psicológico, social, intelectual da criança (ROCHA, 2010).

Organização das Nações Unidas proclamou o ano de 2005, como o Ano Internacional do Esporte e da Educação Física, e isso evidencia o reconhecimento, em nível mundial, da Educação Física e do Esporte como fatores de desenvolvimento educacional, da promoção da saúde, de formação da cidadania e inclusão social das crianças, jovens, adultos e idosos.

A participação de crianças e adolescentes na atividade física vem aumentando a cada dia, embora nos países industrializados, em especial na fase de adolescência, essa participação esteja diminuindo. Para reverter esse processo, torna-se necessário identificar que fatores influenciam na aderência da criança e do adolescente na atividade física, buscando a melhora de sua saúde, e em consequência, melhor qualidade de vida (OLIVEIRA, et al, 2005).

A prática de atividades físicas deve ser estimulada nas crianças e adolescentes diariamente, ou quase todos os dias, mediante jogos, brincadeiras, esportes, trabalho, 
transporte, recreação, aulas de Educação Física ou programa de exercícios físicos, no contexto familiar, escolar e comunitário. No entanto, percebe-se a falta de um maior domínio de conceitos e referenciais teóricos simultaneamente com a prática da atividade motora entre crianças e jovens na escola (PIRES, 2008).

A Disciplina de Educação Física escolar é conhecida tradicionalmente como área das Ciências da Saúde, que sustenta os pensamentos da Educação que regulamenta o âmbito escolar. E necessário que desenvolvemos condições para que o educando possa compreender criticamente suas condições de saúde, utilizando-se do movimento e das relações interpessoais recomendadas pelo processo educativo (GUIMARÃES, 2009).

Ponderar a respeito da educação física como instrumento de inserção no ensino infantil é, acima de tudo, um assunto bastante delicado quando pensamos em docentes de educação física trabalhando com a faixa etária de zero à seis anos do desenvolvimento da criança. Estamos falamos dos docentes especializados e pedagogo, essa perspectiva abre várias discussões sobre até que ponto as duas profissões podem dividir ou compartilhar os conteúdos do ensino infantil (CAVALARO; MULLER, 2009).

Rocha (2010) ressalta que a educação física como instrumento pedagógico na educação infantil é de extrema importância, pois suas temáticas fazem com que o aluno tenha uma gama de vivencias pedagógicas, obtendo formas de relacionamentos em seu convívio, que até então não existia em seu cotidiano, buscando uma concepção a partir da diversidade do movimento. Dentro desta perspectiva, a educação física inserida dentro do âmbito da educação infantil estará efetivando a evolução integral das crianças.

Ainda nesta perspectiva, é primordial que os docentes de Educação Física e os demais gestores escolares, discutam e proponham métodos e técnicas planejadas destinadas à educação visando às questões de obesidade e da promoção de saúde, idealizando e colocando em prática novas tendências visando sanar os problemas existentes no âmbito escolar.

A Educação Física pode ser um dos instrumentos que possa ampliar a Escola como uma instituição Promotora de Saúde, sendo assim, considerado um espaço que estimula e garante uma participação ativa da comunidade escolar, tendo com objetivo central conscientizar as atitudes e ambientes mais saudáveis logo no ensino infantil, visando desenvolver habilidades e estimular a tomada de decisões por meio da responsabilidade individual, familiar e comunitária (GUIMARÃES, 2009). 
Um documento apresentado recentemente, pelo Ministério da Saúde (BRASIL, 2006), descreve algumas experiências brasileiras, no campo da saúde escolar e mostra a importância da reflexão sobre a ação intersetorial da área da Saúde com a da Educação, que prioriza a participação efetiva da comunidade no processo de construção coletiva de ações de saúde na escola e mostra também a importância de levar em consideração os olhares, expressões e saberes diferenciado dos atores envolvidos para concretização de um trabalho efetivo na escola. Registra, também, várias práticas cotidianas, em ações de Promoção da Saúde na escola, provenientes das mais diversas regiões e localidades do Brasil. A riqueza de experiências, práticas ou estratégias, implementadas mostram que algumas escolas cumprem papel importante nas diferentes comunidades de forma significativa para os atores envolvidos.

Neste Seguimento, a Educação em Saúde propõe uma linha de planejamento participativo para as ações educativas, estreitando as relações professor-aluno, com base na problematização, que valoriza a responsabilidade do professor e do aluno sobre a sua saúde, da família e da comunidade.

Segundo o Ministério da Saúde (BRASIL, 2006), as experiências são pautadas em práticas de educação e saúde, que se consolidam com metodologias participativas, possibilitando a construção de ambientes mais saudáveis na comunidade escolar. Apresentam relatos a partir de temas como alimentação, atividade física, cultura da paz, questões relacionadas à violência, sexualidade e prevenção de doenças sexualmente transmissíveis e AIDS, saúde bucal, saúde do adolescente, construção de ambientes saudáveis, práticas relacionadas à comunicação e saúde e a movimentos culturais em suas diferentes linguagens, como teatro, música e dança. Com objetivo de estimular o desejo de mudanças na elaboração de ações de saúde na escola e, particularmente, contribuir para a revisão dos tradicionais programas de saúde escolar.

Ayoub (2001) explica que não se pode contestar a essência da educação física, firmada primordialmente no âmbito da cultura corporal. Se conseguirmos defender essa essência durante a nossa pratica pedagógica sem a intenção de sermos os "donos" da expressão corporal das crianças, com essa tendência, podemos também desencadear o reconhecimento desta área do conhecimento perante a sociedade.

\section{Considerações finais}

Durante o período limitado nas vivências realizadas no Estágio Supervisionado 
no Ensino Infantil, e com a concretização das ações saudáveis pretendidas, eu como futuro Professor de Educação Física Escolar, pude com essa atuação em campo, compreender e ampliar o quanto podemos ofertar de conhecimento para os alunos do Ensino Infantil.

A educação infantil é um âmbito contemplado pelo o profissional pedagogo, mas é notória também, a necessidade da existência dentro deste mesmo espaço a presença dos profissionais de Educação Física, como mais uma área do conhecimento envolvida no processo de ensino aprendizagem e promoção de saúde, os que mais saem ganhando com isso são as próprias crianças porque terão diversidades e complementações de conteúdos de ambos os docentes.

Diante das vivências promotoras de saúde na creche Dolores Lustosa, pode-se deduzir que a Educação Física e a Pedagogia junta no ensino Infantil podem contribuir significativamente com o desenvolvimento dos alunos no processo de ensinoaprendizagem e, na prática e conscientização dos educandos na construção de hábitos saudáveis no âmbito escolar.

\section{REFERÊNCIAS}

ALVES, B. da S.; SILVA, J. A. R. da.; ZOIA, E. T. Reflexões sobre o estágio supervisionado na educação infantil: contribuindo para uma prática educativa humanizadora. Disponível em:

<http://www.histedbr.fe.unicamp.br/acer_histedbr/jornada/jornada11/artigos/9/artigo_si mposio_9_1030_bruna_alvesrodrigues@ hotmail.com.pdf>. Acesso em: 9 abr. 2016.

AYOUB, E. Reflexões sobre a Educação Física na Educação Infantil. Rev. Paul. Educ. Fís., São Paulo, supl.4, p.53-60, 2001.

AZOLINI. L. C. O estágio supervisionado na formação do professor de educação física: um estudo autorreferente de um estudante da ESEF da UFRGS no ano de 2012 (Trabalho de Conclusão de Curso), P. 1-51. Repositório Digital da Universidade Federal do Rio Grande do Sul, Universidade Federal do Rio Grande do Sul, Rio Grande do Sul.

BRASIL. Secretaria de Educação Fundamental. Parâmetros Curriculares Nacionais. Educação física/Secretaria de Educação Fundamental. $5^{\text {a }}$ ed. Brasília: MEC/SEF, 2007.

CAVALARO, A. G.; MULLER, V. R. Educação Física na Educação Infantil: Uma Realidade Almejada. Educar, Curitiba, n. 34, p. 241-250, 2009.

CONSELHO Nacional de Saúde. Resolução No 466, DE 12 de dezembro de 2012. Disponível em: <http://conselho.saude.gov.br/resolucoes/2012/Reso466.pdf〉. Acesso 
em: 18 fev. 2016.

GUIMARÃES, C. C. P. D. Educação Física Escolar e Promoção da Saúde: uma pesquisa participante. (Dissertação de Mestrado), 1-161. Universidade São Judas Tadeu, São Paulo, 2008.

LDB. Lei de Diretrizes e Bases da Educação Nacional. Lei 9394/96. Ed. APP Sindicato, 1997.

OLIVEIRA, A. R.; MARANI, F.; OMORI, M. K;. ONO, M. Y. A promoção de saúde e qualidade de vida na educação básica: um olhar na educação física que temos para a educação física que queremos. Anais do "II CONPEF - Congresso Norte Paranaense de Educação Física Escolar", p. 103-116, 2005. Disponível em: <http://www.uel.br/eventos/conpef/conpef2/CONPEF2005/ARTIGOS/CONPEF2005_ A10.pdf>. Acesso em: 18 fev. 2016.

PIAGET, J. A formação do símbolo na criança. 3 ed. Rio de Janeiro: Zahar Editora, 1978.

PIMENTA, S. G.; LIMA, M. S. L. Estágio e docência: diferentes concepções. Revista Poíesis, [s. n.], v. 3, n. 3, p. 5-24, 2005/2006.

PIRES, B. R. Atividade física em promoção a saúde: uma proposta sobre o conhecimento no âmbito escolar. Revista Digital - Buenos Aires, ano 13, n. 121, 2008.

ROCHA, M. P. Educação física na educação infantil: experiência do estágio supervisionado I na educação infantil em 2010. In: III CONGRESSO NORDESTE DE CIÊNCIAS DO ESPORTE. 2010. Disponível em:

<http://congressos.cbce.org.br/index.php/conece/3conece/paper/viewFile/2463/986>. Acesso em: 24 fev. 2016.

DA SILVA, E. J. S. A educação física como componente curricular na educação infantil: elementos para uma proposta de ensino. Revista Brasileira de Ciências do Esporte, v. 26, n. 3, 2005.

TRIPP, D. Pesquisa-ação: uma introdução metodológica. Educação e pesquisa, v. 31, n. 3, 2005.

VYGOTSKY, L. S. Formação social da mente., São Paulo: Martins Fontes, 1984.

WALLON, H. Psicologia e educação da criança. Vega/Universidade, Lisboa, 1979. 


\section{Como referenciar este artigo}

TEIXEIRA, Francisco Claudeci Faustino et al. Relato de experiência no estágio supervisionado I no ensino infantil. Revista on line de Política e Gestão Educacional, Araraquara, v. 21, n. esp.2, p. 1195-1207, nov. 2017. Disponível em: <http://dx.doi.org/10.22633/rpge.v21.n.esp2.2017.10195>. E-ISSN:1519-9029.

Submetido em: 30/07/2017

Aprovado em: 21/08/2017 